\section{9: ДЕСЯТЬ ГЛАВНЫХ ТРЕНДОВ СВЕТОВЫХ ТЕХНОЛОГИЙ}

\author{
A. Фumep, Novus Light Technologies Today, \\ www.novuslight.com, Нью-Йорк, США, по мате- \\ риалам А. Лахрач, System Plus Consulting, www. \\ systemplus.fr, Yole Development, www.yole.fr
}

\section{9: TOP TEN TRENDS IN LIGHT TECHNOLOGIES"}

\author{
A. Fischer, Novus Light Technologies Today, \\ www.novuslight.com, NI USA, done on materials \\ A. Lahrach, System Plus Consulting, www.systemplus. \\ fr, Yole Development, www.yole.fr
}

\begin{abstract}
Световые технологии находятся в центре внимания современного мира, обеспечивая самые сложные процессы и процедуры. Знакомьтесь - десять наиболее заметных тенденций, которые возглавят список продуктов, ожидаемых на рынке фотоники в 2019 году. Это десять тенденций в применениях световых технологий, каждая из которых являет собой результат цепочки небольших, постепенных достижений, открывающих громадные возможности.
\end{abstract}

\section{ВИЗУАЛИЗАЦИЯ ПРОЦЕССОВ В МОЗГЕ}

Сфера визуализации мозга расширяется по мере продвижения в такие технологии, как голография, трехмерная визуализация, подсчет фотонов, волоконно-оптическое зондирование и имплантируемая МРТ-визуализация. Ожидается, что рынок трехмерных изображений в ближайшие три года вырастет почти на 25\%. И одним из его многочисленных приложений стало исследование мозга. Исследователи из университета ТельАвива (Израиль) разработали решение для счета фотонов, которое улучшает качество быстрой 2D- и 3D-визуализации активности нейронов в живом мозге, пытаясь раскрыть внутреннюю работу интерфейса между нейронами и кровеносными сосудами.

Голография открывает еще одну область возможностей для исследований мозга. Калифорнийский университет в Беркли с помощью лазерного излучения активирует нейроны в мозге, имитируя характер и ритм фактической реакции мозга, и записывает голограмму. Другие исследователи разработали волоконно-оптические датчики, которые могли бы стать альтернативой системам магнитно-резонансной томографии (MPT), используемым для картирования мозговой активности. Поскольку система портатив-

Примечание редактора: публикуется с разрешения Novus Light Technologies Today, публикация Novus Media Today Group, LLC. Оригинал статьи Top Ten Trends in Light Technologies, 2019 размещен 7 января 2019 на веб-сайте Novus Light по адресу: www.novuslight.com. Anne Fischer, Novus Light Technologies Today, www.novuslight.com, по материалам A. Lahrach, System Plus Consulting, www.systemplus.fr, Yole Development, www.yole.fr. ная, недорогая и может работать при комнатной температуре без экранирования оборудования, ее можно использовать прямо в точке воздействия - в спорте для диагностики сотрясений или в зонах конфликта, когда часты травмы головного мозга из-за случаев взрывов.

Группа исследователей из Массачусетского технологического института разработали крошечный датчик, который можно имплантировать в мозг, взаимодействуя с MIR-сканером, расположенным вне тела. Устройство не требует питания или проводного соединения с мозгом, и оно может обнаружить крошечный электрический ток в мозге и оптические сигналы, производимые люминесцентными белками.

\section{АДДИТИВНЫЕ ТЕХНОЛОГИИ}

Аддитивное производство или 3D-печать -развивающаяся технология. По прогнозам аналитиков, к 2023 году темпы ее роста достигнут более $26 \%$ в год. Она будет использоваться во всем: от производства металлических деталей в автомобильной промышленности до проектирования и изготовления оптики на заказ и производства протезов, кровеносных сосудов и клапанов сердца.

В лазерном аддитивном производстве лазеры играют важную роль, потому что они фокуси-

Editor's Note: Material is used with permission of Novus Light Technologies Today. The original article Top Ten Trends in Light Technologies, 2019 is posted on January 7, 2019 on the Novus Light website at: www.novuslight.com. Anne Fischer, Novus Light Technologies Today, done on materials A. Lahrach, System Plus Consulting, www.systemplus.fr, Yole Development, www.yole.fr. 
руют энергию на порошковых материалах самого широкого фракционного состава, сплавляя их слой за слоем в трехмерные детали. Технология Laser Fusion Bed Fusion (LPBF), также известная как селективное лазерное плавление (SLM), находится в центре внимания проекта AutoAdd Института лазерных технологий Фраунгофера (ILT) в Аахене (Германия). Проект AutoAdd направлен на то, чтобы облегчить автомобилестроению использование аддитивного производства за счет интеграции технологической цепочки LPF в среду массового производства автомобилей, чтобы снизить себестоимость единицы продукции.

В области медицины аддитивное производство используется для создания разных типов имплантатов - от лицевых до ортопедических и до стоматологических. Ожидается, что рынок медицинских устройств с 3D-печатью к 2025 году составит около 10 миллиардов долларов США. Исследователи в Великобритании использовали аддитивное производство, чтобы исследовать, как растут наши кости. Создавая модели костей в процессе, имитирующем их реальный рост, они не только узнали, как растут кости, но и узнали, какие элементы их конструкции обеспечивают устойчивость костей к ударам и циклическим изгибам. Результаты этих исследований могут, во-первых, привести к появлению имплантатов, более близких к естественным органам, способным заменить используемые сегодня металлические и пластиковые имплантаты. Во-вторых, исследования могут также помочь в понимании процессов возникновения остеопороза и разрушения кости.

\section{КВАНТОВЫЕ ТЕХНОЛОГИИ}

Цифровые технологии изменили компьютеры, коммуникационное оборудование, безопасность, медицину и многое другое. Теперь мы переходим от цифровых технологий к квантовым технологиям. В микроэлектронике и оптоэлектронной технике используются классические принципы представления и обработки информации. Квантовые информационные технологии опираются на более тонкие эффекты - квантовые корреляции, запутанность и суперпозиция квантовых состояний, запрет клонирования неизвестных квантовых состояний.

Значительное государственное финансирование направляется странами на развитие квантовых технологий и поддержку проектов, которые приведут эти технологии к коммерциализации. Например, в Европе это проект Quantum Flagship инициатива стоимостью 1 миллиард евро, в которой примут участие более 5000 европейских исследователей. Проект рассчитан на 10 лет. ПроeкT UNIQORN один из многих, входящих в состав Quantum Flagship. Он сосредоточится на кван товых системах связи. Его миссия заключается в создании методов, позволяющих связывать квантовые коммуникации с фотонными технологиями, помещая сложные системы в микросхемы миллиметрового размера.

И еще одна европейская группа объединяет усилия для развития искусственного интеллекта и квантовых вычислений. Imec и CEA-Leta подписали соглашение, направленное на разработку, тестирование и эксперименты с нейроморфными и квантовыми вычислениями. Они намерены предоставить набор инструментов для цифровых аппаратных вычислений, который может использоваться европейскими отраслевыми партнерами для инноваций в различных приложениях - от персонализированного здравоохранения и умной мобильности до систем новой обрабатывающей промышленности и умных энергетических секторов. И, хотя многие иссле- 
довательские группы находятся в стадии формирования, созданные группы уже демонстрируют разработки фотонного чипа с помощью топологических схем, способного кодировать, обрабатывать и передавать на расстояния квантовую информацию.

\section{ДОПОЛНЕННАЯ \\ РЕАЛЬНОСТЬ/ВИРТУАЛЬНАЯ РЕАЛЬНОСТЬ}

Поскольку цифровые технологии становятся частью нашей повседневной жизни, мы будем все больше контактировать с виртуальной, дополненной и даже смешанной реальностью. Что это такое, и чем они отличаются? Виртуальная реальность погружает пользователя в другой мир. Надев головной экран или установив на голове дисплей, пользователь оказывается в виртуаль ной среде, например в видеоигре или в медицинском учреждении. Дополненная реальность (additive real AR) накладывает изображения объекта на вид реального мира. Смешанная реальность, как следует из названия, смешивает виртуальное изображение с изображением реального мира, позволяя пользователю взаимодействовать с программными изображениями.

VRHealth предоставляет решения виртуальной реальности для больниц, реабилитационных центров и кабинетов врачей. Приложения VR доступны для управления болью, реабилитационных упражнений, терапии для детей, страдающих церебральным параличем, и многого другого. Проект VOSTARS (видеооптическая прозрачная хирургическая система дополненной реальности) разрабатывает медицинское оборудование для использования во время проведения хирургических операций. Наложив рентгеновский снимок пациента в унисон с его телом, хирургам не нужно отвлекаться во время операции. Дополнительное удобство предоставляют выведенные на такой дисплей данные анестезии пациента, частоты сердечных сокращений, температуру тела и параметры других жизненно важных органов. Проект прогнозирует улучшение точности, а также сокращение времени в операционной. Возможности медицинских технологий будут безгранично расти с развитием приложений AR/VR/MR. Head-Display-дисплеи являются неотъемлемой частью новых медицинских приложений, и, как следствие, ожидается, что к 2024 году рынок Head-Display-дисплеев превысит 7 миллиардов долларов США, увеличившись за тот же период более чем на $19 \%$.

\section{ПОЛЯРИЗАЦИОННЫЕ КАМЕРЫ}

Сегодня специалисты наблюдают высокую степень специализации в области камер. Прошли те времена, когда значение имели более крупные CMOS-сканеры. Сегодня все зависит от того, что может делать камера. Следствием этой тенденции стало появление узкоспециализированных имидж-сканеров, которые можно использовать во времяпролетных фотокамерах и поляризационных камерах.

В поляризационных камерах построение изображения происходит по тем же правилам, что и в глазах насекомых. Насекомые, например богомол, имеют зрительную систему, которая способна воспринимать информацию о поляризации с помощью светочувствительных клеток, обладающих высоким динамическим диапазоном. Поляризационные камеры полезны для автоматизации индустрии в промышленном контроле, где могут встречаться объекты с низким контрастом или высоким отражением. Поляризационные камеры могут фильтровать углы поляризации от света, отражаемого поверхностями различных материалов. Камеры подходят для оборудования контроля шероховатости и формы деталей со сложной кривизной поверхности, например лопастей.

Sony сделала шаг вперед с появлением глобального CMOS-датчика, создав затвоp Sony iMX250MZR, который предоставляет производителям камер готовое решение, вместо того чтобы устанавливать вращающееся колесо механического поляризационного фильтра над датчиком в камере.

\section{ЛИДАРНОЕ ЗОНДИРОВАНИЯ}

Согласно последнему отчету ResearchandMarkets, в ближайшие десять лет мировой рынок автомобильных лидаров (LIDAR - англ. LIght Detection And Ranging) будет расти в среднем на 29,6\%. Рынок обусловлен ростом числа автономных транспортных средств и усовершенствованных систем помощи водителю (ADAS), особенно в свете растущего числа случаев, связанных с безопасностью транспортных средств без водителя.

Лидар позволяет обнаружить и определить дальность источника света и используется либо вместо камер, радаров и ультразвуковых датчиков, либо в дополнение к ним. Сенсорные технологии дополняют друг друга и обеспечивают наилучшую возможную надежность для дневного и ночного вождения. Возможности на 
этом рынке кажутся безграничными. Известные компании по производству оптики, такие как Jenoptik, поставляют ряд оптических элементов, которые используются в современных лидарных системах. Hamamatsu поставляет четырехканальный импульсный лазерный диод, который может использоваться в качестве источника света для автомобильных лидарных модулей, что позволяет более точно измерять объекты на больших расстояниях. Laser Components, поставщик лазерных и оптоэлектронных компонентов, сотрудничает с Институтом микроэлектронных схем и систем, входящим в состав Института Фраунгофера, в разработке лидаров. Excelitas предлагает устройство импульсного лазерного диода для поверхностного монтажа в качестве ключевого элемента лидарных систем следующего поколения. Компании по нанесению покрытий, такие как AccuCoat, занимаются уникальными потребностями оптических покрытий в лидарных системах. И этот список можно продолжать по мере расширения технологий и роста рынка.

\section{УПРАВЛЕНИЕ ОСВЕЩЕНИЕМ}

Если говорить о достижениях в сегодняшнем освещении, то все они относятся к контролю - интеллектуальные светильники, интеллектуальное освещение, умный дом и т.д. Зная характеристики твердотельных источников освещения, можно контролировать интенсивность света, цветовую температуру излучения, его оттенок (теплый или холодный), энергопотребление и многие другие параметры. Управление освеще- нием может быть встроено в драйвер светодиода, оно может управляться компьютером или отключаться в интернет-облаке.

Область применения управления освещением варьируется от интеллектуального освещения в зданиях до промышленного машинного зрения и освещения помещений сельского хозяйства (теплиц, коровников, помещений для птиц). В машинном зрении постоянные уровни освещения имеют решающее значение, поскольку системы машинного зрения должны очень точно контролировать, проверять, анализировать и классифицировать. Внутренние сельскохозяйственные приложения позволяют ускорить рост продукции или повысить эффективность за счет подавления роста болезнетворных патогенных организмов. Компания Cortet, специалист по технологиям интеллектуального построения интернета вещей (IoT), разработала решение Cortet Lighting Control, которым можно управлять с помощью мобильного приложения. Gardasoft предлагает серию контроллеров освещения, соединенных с интеллектуальной камерой. система позволяет управлять освещением помещения и быстро визуализировать картину его освещенности при варьировании различными индикатрисами излучателей.

\section{ГЛУБОКОЕ ОБУЧЕНИЕ}

В бизнесе программного обеспечения (ПО) многих производителей и компаний, занимающихся машинным обучением и глубоким обучением, наблюдается революция. Существует различие между двумя системами ПО: ПО для машинного 
обучения, использующего машины опорных векторов (SVM) или алгоритмы Random Forest, и ПО для глубокого обучения с использованием архитектуры нейронных сетей - сверточных нейронных сетей (CNN) (класса нейронных сетей, которые очень подходят для анализа визуальных образов).

ПО для глубокого обучения, используемое в системе виденья, будет обучено выполнению очень специфических функций, выявлению сложных функций и соответствующей классификации изображений. На примере крупных компаний видно, как производство двигается в направлении глубокого обучения. Hyundai CRADLE (компания, входящая в Hyundai Motor Company и занимающаяся корпоративными предприятиями и открытыми инновациями) недавно инвестировала крупную сумму в Allegro.ai, технологическую компанию, специализирующуюся на глубоком обучении. Matrox Imaging недавно объявила о том, что ее прикладное ПО для визуализации реализовано на блоксхемах Matrox Design Assistant X и объединяет новые функциональные возможности, включая классификацию изображений с использованием глубокого обучения. EyeVision стала примером создания ПО машинного зрения для распознавания номерных знаков, а также марок и моделей автомобилей.

\section{МИНИСПЕКТРОМЕТРЫ}

Спектроскопия - это метод, используемый для измерения интенсивности излучения в ВУФ-, УФ-, видимом и ИК-диапазонах. Метод используется в широком спектре приложений - от медицины, охраны окружающей среды, безопасности, фармакологии до исследований в астрофизике и многом другом. Спектроскопия восходит к оптическому эксперименту Исаака Ньютона в 1600-х годах, но быстро продвигалась вперед. И сегодня на рынке спектрометрического оборудования наблюдаются небольшие мини- и микроспектрометры, которые позволяют проводить измерения на месте в реальном времени.

Даже в крошечных упаковках маленькие спектрометры имеют высококачественную оптическую конструкцию, которая обеспечивает стабильность и высокое оптическое разрешение. Пример разработок в этой области демонстрирует европейский проект InSPECT, в котором исследователи разработали два класса спектрометрических систем: компактный кубический дюймовый спектрометр на основе дифракционной оптики и спектрометрическую систему на основе Si-волноводной технологии TriPleX, включающей спектрометр на фотонной интегральной схеме. Кроме того, был разработан новый класс широкополосных источников света, основанный на твердотельном лазерном возбуждении люминесцентных материалов. Новое поколение экономически эффективных решений обеспечивает спектральное зондирование для хирургов в операционной, для врачей в консультационных кабинетах и для врачей в удаленных медицинских центрах.

В дополнение к производству компактных спектрометров производители предлагают линейки продуктов, ориентированные на пользователей. Такие продукты предназначены для конкретного решения, достаточно просты в обращении, чтобы ими могли пользоваться специалисты, не занимающиеся спектроскопией.

\section{УМНАЯ ФАБРИКА}

Умная фабрика, Индустрия 4.0, Интернет вещей все это относительно новые термины, которые описывают современный способ производства. Сегодня мы живем в так называемой 4-й промышленной революции, отсюда Индустрия 4.0. Первая революция увидела раннюю механизацию, управляемую водой и паром. Во второй - массовое производство началось со сборочных линий, управляемых электричеством. Третья - была новой волной компьютеризации и автоматизации. И сегодня четвертая революция включает кибер-физические системы, соединенные через Интернет и облачные вычисления.

Световые технологии играют центральную роль, обеспечивая оптическую связь, системы 3D-визуализации, интеллектуальные лазеры, оптические датчики, оптоволокно, роботизированные автономные системы и многое другое. По-настоящему умные фабрики обрели реальные возможности благодаря слиянию современных светотехнических технологий: визуализации, распознавания образов, контролю и возможности управления из любой точки мира.

\section{ЗАКЛЮЧЕНИЕ}

В отдельности каждый тренд представляет собой важные достижения, полезные приложения и многообещающие технологии, расширяющие наши возможности. В совокупности эти десять тенденций подчеркивают значимость световых технологий почти во всех аспектах нашей жизни, и они, несомненно, будут играть все большую роль в будущем. 